\title{
Cerebral blood flow in diabetes mellitus: evidence of abnormal cerebrovascular reactivity
}

\author{
P DANDONA, I M JAMES, P A NEWBURY, M L WOOLLARD, A G BECKETT
}

British Medical fournal, 1978, 2, 325-326

\section{Summary and conclusions}

Cerebral blood flow (CBF) was studied at normocapnia and after a challenge with $5 \% \mathrm{CO}_{2}$ in 59 diabetic patients and 28 controls. There was a significant age-related decline in CBF in both groups, which suggests that diabetes does not affect the rate of decrease of $C B F$ with age. After $\mathrm{CO}_{2}$ challenge $\mathrm{CBF}$ increased in most of the controls; in the patients CBF increased in 23, decreased in 26, and remained stable in 10 . Thus the reactivity of cerebral blood vessels in diabetics is altered.

Diabetics have diminished cerebrovascular reserve and are thus at increased risk of cerebrovascular disease because they are unable to compensate when necessary with an increased $\mathrm{CBF}$.

\section{Introduction}

In view of the high incidence of cerebrovascular disease in diabetics ${ }^{1-3}$ we decided to study cerebral blood flow (CBF) in patients with diabetes mellitus and control patients. We investigated the flow at normocapnia and the vasodilatation reserve in response to hypercapnia. We also assessed the effect of age on flow in both groups.

\section{Subjects and methods}

We studied 59 diabetic patients aged 14-74 (mean 46) years and 28 controls aged 18-80 (mean 43) years. None of the patients had overt cardiovascular disease or erythrocytosis. Informed consent was obtained from patients and controls, and the study was approved by the ethical committee.

$\mathrm{CBF}$ was measured by the ${ }^{133} \mathrm{Xe}$-inhalation method of Wyper et al. ${ }^{4}$ This technique combines the inhalation method pioneered by Mallett and Veall ${ }^{5}$ and Obrist et $a l^{6}$ with the initial slope method of Paulson et al. ${ }^{7}$ Corrections for arterial recirculation of the gas were made by monitoring the radioactivity of the end-tidal air. Deconvolutional analysis of the decay curves was carried out using a three-dimensional normogram. ${ }^{8}$ The inhalation period lasted only two minutes, so that the gas was principally carried to highly perfused organs such as the brain. Error due to extracranial contamination by the isotope was thus minimised. Results obtained in this way compare favourably with those obtained by the more direct but unacceptably traumatic method of puncturing the internal carotid artery. ${ }^{4}$ End-tidal $\mathrm{CO}_{2}$ tensions were measured with a Beckman infrared $\mathrm{CO}_{2}$ analyser. The subjects rested supine before measurements were begun. Recordings were made at normocapnia and during inhalation of $5 \% \mathrm{CO}_{2}$. Haemoglobin concentrations were measured in all patients.

\section{Royal Free Hospital, London NW3 2QG}

P DANDONA, MRCP, DPHIL, director of metabolic unit and senior lecturer in clinical pathology

I M JAMES, PHD, FRCP, senior lecturer in medicine and therapeutics $P$ A NEWBURY, research assistant

$M$ L WOOLLARD, research assistant

A G BECKETT, BM, FRCP, consultant physician

\section{Results}

$\mathrm{CBF}$ at normocapnia was similar in the diabetic patients and controls. There was a significant reduction in CBF with age in the diabetics $(\mathrm{r}=-0.83, \mathrm{P}<0.001$ - fig 1 ), which was similar to that in the normal population ( $\mathrm{r}=-0.77, \mathrm{P}<0.001-\mathrm{fig} 2)$. The regression of $\mathrm{CBF}$ with age was given by $\mathrm{CBF}=60.8-(0.33 \times$ age $)$ in controls and $\mathrm{CBF}=71.03-(0.48 \times$ age $)$ in diabetics. Some of the diabetics,

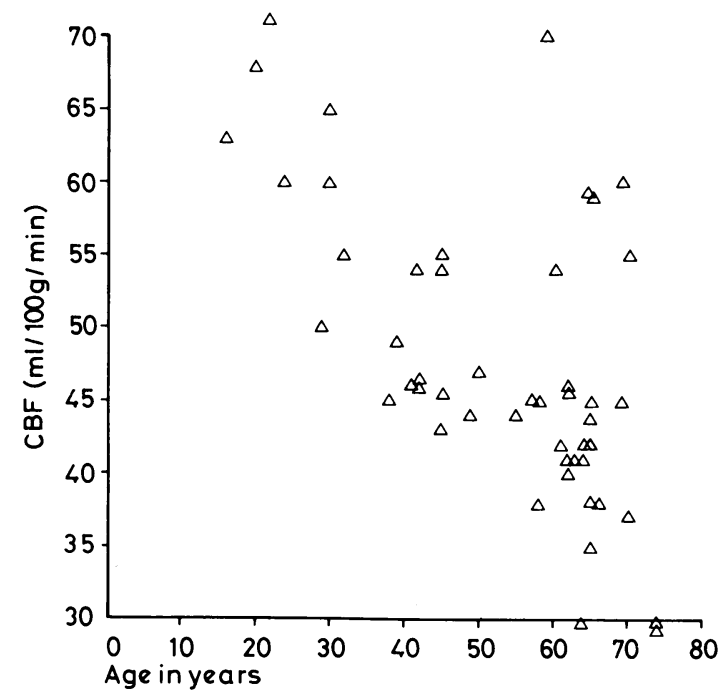

FIG 1-Decline of CBF with age in diabetics.

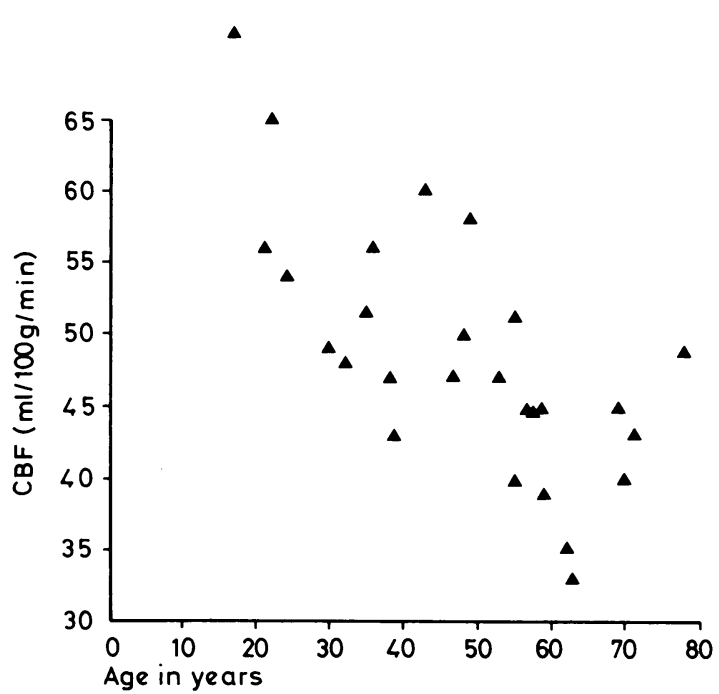

FIG 2-Decline of CBF with age in control patients.

however, appeared to maintain $\mathrm{CBF}$ at levels higher than would be expected for their age. Haemoglobin concentration did not increase with age.

In all but four of the controls there was a significant increase in 

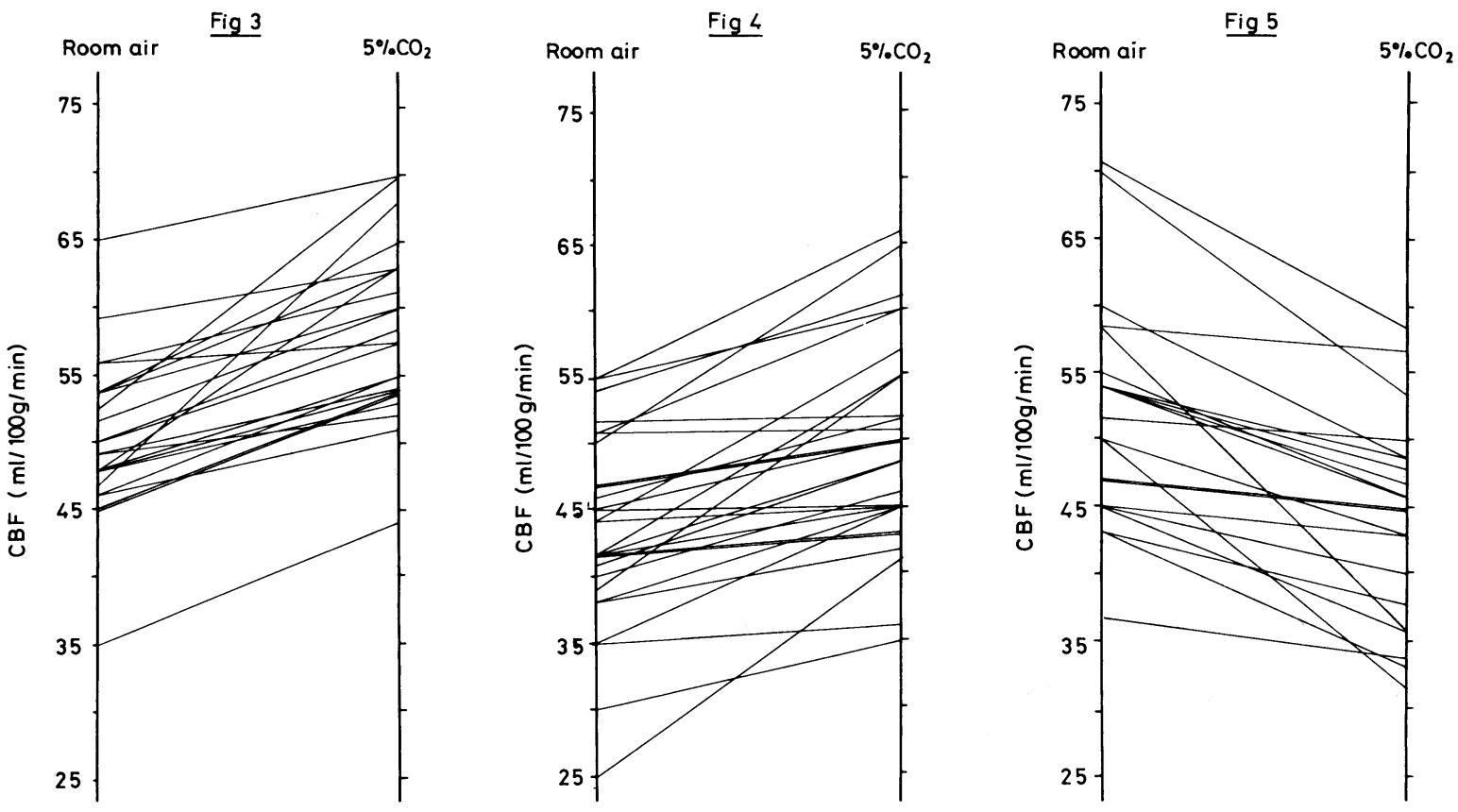

FIG 3-Effect of $5 \% \mathrm{CO}_{2}$ on $\mathrm{CBF}$ in controls. (Mean $\pm \mathrm{SE}$ of mean expired $\mathrm{PcO}_{2}$ : room air $4 \cdot 40 \pm 0 \cdot 20 \mathrm{kPa}(33 \cdot 1 \pm 1 \cdot 5 \mathrm{~mm} \mathrm{Hg})$; $5 \% \mathrm{CO}_{2} 5 \cdot 46 \pm 0 \cdot 20 \mathrm{kPa}(41 \cdot 1 \pm 1 \cdot 5 \mathrm{~mm} \mathrm{Hg})$.) FIG 4 -Effect of $5 \% \mathrm{CO}_{2}$ on $\mathrm{CBF}$ in diabetics with normal $\mathrm{CO}_{2}$ reactivity. $(\mathrm{Mean} \pm$ $\mathrm{SE}$ of mean expired $\mathrm{PCO}_{2}$ : room air $4 \cdot 29 \pm 0 \cdot 16 \mathrm{kPa}(32 \cdot 3 \pm 1 \cdot 2 \mathrm{~mm} \mathrm{Hg}) ; 5 \% \mathrm{CO}_{2} 5 \cdot 50 \pm 0 \cdot 16 \mathrm{kPa}(41 \cdot 4 \pm 1 \cdot 2 \mathrm{~mm} \mathrm{Hg})$.) $\mathrm{FIG} 5-$ Effect of $5 \% \mathrm{CO}_{2}$ on $\mathrm{CBF}$ in diabetics with abnormal $\mathrm{CO}_{2}$ reactivity. (Mean $\pm \mathrm{SE}$ of mean expired $\mathrm{PCO}_{2}:$ room air $4 \cdot 36 \pm 0 \cdot 15 \mathrm{kPa}$ $\left.(32 \cdot 8 \pm 1 \cdot 1 \mathrm{~mm} \mathrm{Hg}) ; 5 \% \mathrm{CO}_{2} 5 \cdot 58 \pm 0 \cdot 19 \mathrm{kPa}(42 \cdot 0 \pm 1 \cdot 4 \mathrm{~mm} \mathrm{Hg}).\right)$

$\mathrm{CBF}$ after challenge with $5 \% \mathrm{CO}_{2}$ inhalation (fig 3). Among the diabetics challenge with $\mathrm{CO}_{2}$ led to an increase in $\mathrm{CBF}$ in 23 patients (fig 4), a decrease in 26 , and no change in 10 (fig 5).

\section{Discussion}

Our observations indicate a significant age-related decline in $\mathrm{CBF}$ in both controls and diabetics. The values of CBF and the rates of decline were similar to those found by Crawley and Veall $^{9}$ in normal people. The slopes of regression lines for diabetics and controls were similar in our study, suggesting that diabetes does not significantly alter the rate of decline of normocapnic CBF with age. Increased viscosity of the blood has been found in diabetic patients, suggesting that blood flow through organs of diabetics may be impaired. ${ }^{10}$ Increased viscosity due to a high packed cell volume may also be associated with reduced CBF. ${ }^{11}$ Since CBF was normal other factors may compensate for increased viscosity in diabetes. The reactivity of cerebral vessels to $\mathrm{CO}_{2}$ is noticeably altered in diabetics, most of whom show either no increase or a decrease in flow after $\mathrm{CO}_{2}$ administration. The effect of blood viscosity on cerebral vascular reactivity needs to be investigated.

Whereas rapidly developing atherosclerosis with loss of elasticity and ability to dilate may account for the loss of vascular reactivity in older diabetics, this is unlikely to be the cause in younger patients. Furthermore, the paradoxical fall in $\mathrm{CBF}$ after inhalation of $\mathrm{CO}_{2}$ suggests that the latter has a biphasic effect on cerebral blood vessels. Thus some form of neurohumoral dysregulation or alteration in receptors on vascular smooth muscle is probably the cause of altered reactivity of cerebral vessels in diabetes. Newly discovered diabetics without autonomic neuropathy, retinopathy, or other complications also had the abnormality. Since this loss of reactivity was not observed in even the very elderly controls, it appears to be linked specifically to diabetes. A loss of $\mathrm{CO}_{2}$ reactivity has been described in patients with encephalopathy, as in hepatic coma, but the control of these diabetics was reasonable, and none exhibited significant neurological disturbance.

Because the rate of decline of normocapnic CBF with age in diabetics is similar to that in the normal population and the response to $\mathrm{CO}_{2}$ is altered diminished, we suggest that fure studies assessing risk factors in cerebrovascular disease should include $\mathrm{CO}_{2}$ reactivity as an additional indicator of diminished cerebrovascular reserve.

These findings are clinically relevant: although the rate of overt cerebrovascular disease increases with age in both normal patients and diabetics, the diabetics are at particular risk because of their inability to compensate with increased CBF when metabolic requirements of the brain demand this. Similarly the response to hypotension /might be affected if vasodilatation. were compromised.

The impaired ability of cerebral vessels to dilate is an early and undescribed complication of diabetes mellitus, which may be important in the pathogenesis of cerebrovascular disease in diabetics.

We are grateful to the British Diabetic Association for supporting this investigation and for providing a research assistantship for one of us (PAN).

\section{References}

${ }^{1}$ Hayward, R E, and Lucena, B C, fournal of the Institute of Actuaries, $1965,91,286$

${ }^{2}$ Marks, H H, in foslin's Diabetes Mellitus, ed A Marble et al, 11th edn, p 226. Philadelphia, Lea and Febiger, 1971.

${ }^{3}$ Garcia, M, et al, in Vascular and Neurological Changes in Early Diabetes Mellitus, ed R A Camerini-Davalos and H S Cole, p 493. New York and London, Academic Press, 1973.

4 Wyper, D J, Lennox, G A, and Rowan, J O, fournal of Neurology, Neurosurgery and Psychiatry, 1976, 39, 141.

${ }^{5}$ Mallet, B L, and Veall, N, Clinical Science, 1965, 29, 179.

${ }_{6}$ Obrist, W D, et al, Circulation Research, 1967, 20, 124.

7 Paulson, O B, et al, fournal of Nuclear Medicine, 1969, 10, 164.

8 Wyper, D J, and Rowan, J O, Physics in Medicine and Biology, 1976, 21, 406.

${ }^{9}$ Crawley, J C, and Veall, N, Fournal of Nuclear Biology and Medicine, 1975, 19, 205.

10 Barnes, A J, et al, Lancet, 1977, 2, 789.

11 Thomas, D J, et al, Lancet, 1977, 2, 941. 